DOI:

\title{
Kredi Temerrüt Takası İle Ülke Alt Sektör Endeksleri Arasındaki İlişkilerin Belirlenmesi: BIST'te Yer Alan Sektörler Üzerinde Analitik Bir Ínceleme*
}

\author{
Yaşar KÖSE** \\ Murat ATIKK**
}

\section{ÖZET}

Bu çalışmanın amacı Kredi Temerrüt Takası (CDS) puan değerleri ile ülkede bulunan birincil ve alt sektör endeksleri arasında herhangi bir etkileşimin olup olmadiğının incelenmesidir. Çalışmada Türkiye'nin ülke olarak borçlanma maliyetini temsil eden CDS primi değeri ile ülkenin ekonomisinin temel göstergeleri olan birincil sektör endeks değerleri arasindaki iliş̧i incelenmiş ve CDS Puan değerleri ile incelenen yaklaşık tüm sektör endeks değerleri arasında karşıllklı nedensellik iliş̧kisinin bulunduğu tespit edilmişstir. Bu durum ülke CDS primleri yüksekliğinin ülkede mal ve hizmet üreten tüm sektörlerdeki şirketlerin faaliyetleri için kaynak maliyetlerini olumsuz yönde etkilediğini ve ayn zamanda ülkedeki üretim sektöründeki değişimlerin ülke derecelendirme notların ve dolayısıyla bunun da CDS puanını etkilediği şeklinde değerlendirilmiştir.

Anahtar Kelimeler: Kredi Temerrüt Swapı, BIST Alt Sektör Endeksi, Granger Nedensellik Testi.

JEL Siniflandirmasi: F34, E44,C20.

\section{Determining The Relations Between Credit Default Swap (CDS) and Country} Sub-Sector Indices: An Analytical Review on The Sectors in BIST

\section{ABSTRACT}

The purpose of this study is to determine whether there is any interaction between the Country Credit Default Swap (CDS) score values and the primary and sub-sector indices in the country. In this study, it was sound hat there is there is a causality relationship between CDS score values and about all industry index values analyzed after examining CDS values representing the borrowing costs in Turkey and the relationship between primary sector index values, which are the basic indicators of the country's economy.This situation can be evaluated as the high country CDS premium negatively affects the resource cost for the activities of companies in all sectors that produce goods and services in the country, and similarly, changes in the production sector in the country affect the country rating and thus the CDS score value.

Keywords: Credit Default Swap, BIST Sub-Sector Indices, Granger Causality Test

Jel Classification: F34, E44,C20.

\footnotetext{
* Bu makale, 23-25 Nisan 2021 tarihleri arasında gerçekleștirilen VI. Uluslararası Muhasebe ve Finans Sempozyumunda bildiri olarak sunulmuştur.

Makale Gönderim Tarihi: 28.05.2021, Makale Kabul Tarihi: 01.07.2021, Makale Türü: Nicel Analiz

** Doç.Dr., Türk Hava Kurumu Üniversitesi, İşletme Fakültesi, ykose@thk.edu.tr, ORCID: 0000-0003-00732095.

*** Doç.Dr., Milli Savunma Üniversitesi, matik@kho.edu.tr, ORCID: 0000-0002-5150-0203.
} 


\section{GİRiş}

Ülkelerin kredi risklerinin ölçülmesinde ve yatırımcıların ülkelere ilişkin risk algısının değerlendirilmesinde CDS (Credit Default Swap) primlerinden faydalanılmaktadır. CDS şeklinde tanımlanan kredi temerrüt swapları bir nevi alıcısını korumayı amaçlayan bir sigortalama işlemidir. Kredi temerrüt swapları, borçlunun borcunu ödememesi veya ödeyememesi riskine karşılık alacaklı tarafın alacağını garanti altına almak için yaptırmış olduğu bir sigortalama işlemidir. CDS alıcısı, satan tarafa CDS ömrü boyunca CDS puanı (CDS Spread) olarak tanımlanan bir dizi ödeme yapmayı kabul etmektedir.

Özellikle ülke içindeki siyasi, ekonomik ve finansal göstergelerin bozulması uluslararası yatırımcıların piyasalardan çıkmasına, likidite sorunlarının yaşanmasına, risk prim ve kaynak maliyetlerinin artmasına sebep olabilmektedir. CDS primleri bu açıdan bir ülkedeki reel ekonomik ve finansal performansı doğru bir şekilde yansıtabilecek önemli bir gösterge niteliğindedir. CDS primlerinin ülke kredi risklerinin tespitinde genellikle kullanılma sebebi de bu yüzdendir (Akkaya, 2017:130-131).

$\mathrm{Bu}$ çalışmanın amacı CDS primlerindeki değişimlerin sermaye piyasaları üzerindeki etkilerini ortaya çıkarmak için Türkiye'nin 5 yıllık günlük bazda değişen CDS değerleri ile Borsa İstanbul'daki birincil ve 20 alt sektörün günlük endeks değerleri ile etkileşimlerini nedensellik ilişkisi çerçevesinde açıklanmaya çalışılmıştır.

Dünyada ve Türkiye'de CDS ile ilişkileri ortaya çıkaran çalışmalar mevcuttur. Bu çalışmalar ülkelerin kredi risklerinin anlaşılmasında önemli veri sağlayarak kredi risklerinin farklı açılardan değerlendirilmesine olanak vermektedir. 2000’li y1llarda ülkelerin kredi risklerini ölçmek amacıyla kredi derecelendirme kuruluşları tarafından yapılan kredi değerlendirme notları kullanılırken özellikle kriz zamanlarında bu kuruluşların öngörülerinin yetersiz ve güncel durumu göstermemesi ülkelerin kredi risklerini değerlendirmede farklı arayışlara yönelmeleri sonucu CDS'lere olan ilgi artmıştır. CDS sözleşmelerinin finansal riski göstermesi ve diğer kullanılan risk değerlendirme değişkenlerden ayıran önemli özelliklerden birisi günlük olarak piyasadaki her durumu değerlendirerek çok hızlı bir şekilde her yeni durumun primlere yansitabilmesidir. Bu durum ülkelerin CDS primlerine verdikleri önemi derecesini arttırmasındaki önemli unsurdur.

\section{LITERATÜRÜN İNCELENMESI}

Byström (2005) yaptığı çalışmada, Haziran 2004 ile Nisan 2005 yılları arasında 10 aylık bir dönemdeki yedi sektörel Avrupa iTraxx CDS spread endeksi ile dünyadaki 125 çokuluslu şirketin hisse senedi fiyatları arasındaki ilişkiyi incelemiş ve hisse senetleri fiyatları ile CDS spread endeksleri arasında ters yönlü bir korelasyon olduğunu tespit etmiştir.

Križanič ve Oplotnik (2015) tarafından yapılan başka bir çalışmada 2009 ile 2012 yılları arasında Almanya, İngiltere, Rusya ve Slovenya'da CDS puanları ile bu ülkelerdeki makroekonomik değişkenler arasındaki ilişkiler incelenmiş; işsizliğin İngiltere, Rusya ve Slovenya'daki CDS puanlarını etkileyen en önemli değişken olduğu, Almaya CDS puanını etkileyen herhangi bir makroeonomik faktörün bulunmadığını belirlemişlerdir. 
Norden ve Weber (2004) yaptıkları çalışmada hisse senedi ve CDS piyasalarının, 2000-2002 dönemindeki üç büyük derecelendirme kuruluşu (Standard \& Poors, Moodys ve Fitch) tarafından yapılan derecelendirme duyurularına tepkisi analiz edilmiş; Standard \& Poors ve Moodys not düşürme için incelemede bulunduğunda, her iki piyasanın bundan etkilendiğini; daha önce yapılmış ve bir önceki derecelendirmelerden sadece CDS piyasalarının etkilendiğini bulmuşlardır.

Lau ve Kim (2004) çalışmalarında; 19 Mart 2001 ile 29 Mayıs 2003 tarihleri arasında Brezilya, Bulgaristan, Kolombiya, Meksika, Filipinler, Rusya, Türkiye ve Venezuella'dan oluşan 8 gelişmekte olan ülkede yapılan araştırmada söz konusu ülkelerin 5 yıllık CDS Primleri ile hisse senedi fiyatları arasında ters yönlü (negatif) korelasyon olduğunu belirlemişlerdir.

Türkiye’de konu ile ilgili Evci (2020) tarafından yapılan çalışmada ise Türkiye'nin beş y1l vadeli CDS primleri ile BİST100 endeksine ait Ocak 2010-Temmuz 2019 tarihleri arasındaki günlük kapanış değerleri kullanılarak, değişkenler arasındaki uzun dönemli denge ilişkisi Johansen Eşbütünleşme Yöntemi ile, kısa dönem ilişkisi ve bu ilişkinin yönü ise Granger Nedensellik testi ile analiz edilmiş; Johansen Eşbütünleşme analizine göre CDS primleri ile BİST100 endeksi arasında uzun dönem denge ilişsisinin varlığı ve değişkenler arasında ters yönlü bir ilişkinin bulunduğu, Granger nedensellik testine göre kısa dönemde ilişkinin yönünün CDS primlerinden BİST100 endeksine doğru olduğunu tespit edilmiştir.

Sarı̈ül ve Şengelen (2020) tarafından yapılan başka bir çalışmada ise, Türkiye'nin CDS primleri ile BIST Banka Fiyat Endeksi ve 5 adet bankanın hisse senedi fiyatları arasındaki kısa ve uzun dönemli ilişki araştırılmış ve ülke riski algısının belirtilen piyasa üzerindeki etkileri analiz edilmiş, CDS primlerinin uzun dönemde BİST Banka Endeksi ile araştırılan beş bankanın hisse senedi fiyatlarına etkileri olduğu belirlenmiştir.

Akkaya (2017) çalışmasında kredi risk primini etkileyen değişkenleri belirlemek amacıyla Ocak 2008- Mart 2016 dönemleri arası için ABD dolar kurundaki ve Gelişen Piyasalar Tahvil Endeksi (Emerging Markets Bond Index) Türkiye endeksindeki aylık değişimlerin, 5 yıllık ABD Tahvil CDS primleri üzerinde etkisinin olduğunu tespit etmiştir.

İskenderoğlu ve Balat (2018) yaptıkları çalışmada, olay analiz yöntemi ile Ocak 2013 ile Mart 2018 tarihleri arasındaki uluslararası derecelendirme şirketleri (Moody’s, S\&P ve Fitch) tarafından Türkiye ve BRICS (Brezilya, Rusya, Hindistan, Çin ve Güney Afrika Cumhuriyeti) ülkelerine verilen kredi notlarının ülkelerin CDS primleri üzerinde etkisinin olup olmadığını incelemişlerdir. Sonuç olarak ülke kredi notundaki yükseliş veya düşüş şeklindeki değişikliğin 21 günlük dönem zarfı içinde CDS primleri üzerinde artışa sebep olduğunu bulmuşlardır.

Yağcılar ve Arslan (2020) çalışmalarında, Türkiye ve BRICS ülkelerinin ülke riskleri arasındaki etkileşimi göstermek için söz konusu ülkelerin 15 Aralık 2015 ile 18 Mayıs 2020 tarihleri arasında CDS primlerini kullanarak eşbütünleşme ve nedensellik analizleri yapmışlar ve sonuç olarak Türkiye ile Brezilya ve Rusya CDS primleri arasında eşbütünleşmenin yani uzun dönemli bir ilişkinin varlığını tespit etmişlerdir. 


\section{METODOLOJİ VE VERİ SETİ}

Bu çalışma Türkiye'nin 5 y1llık CDS puan değeri ile BIST'deki 20 alt sektörün 30.03.2018- 04.12.2020 tarih aralığındaki günlük endeks değerleri ile aynı tarihler arasındaki 5 yıllık günlük CDS prim değerleri arasındaki ilişsileri nedensellik analizi yöntemi kullanılarak incelenmiştir. Türkiye CDS puan değerleri 6 aylık, 1,2,3,4,5,7,9,10,20 yıllık ve 30 y1llık olarak hesaplanmakta olup, bu değerler içinde literatürde sıklıkla ele alınan ve süre açısından temsil yeteneği en yükssek olan 5 yıllık CDS değerleri analize dahil edilmiştir. Çalışmada ele alınan veriler BIST Türkiye birincil endekslerde yer alan 20 adet birincil sektörün (basit metaller, bankalar, bilgi teknolojileri, elektrik, finansallar, gayrimenkul yatırımları, hizmet holding ve yatırımlar, kimyasal, petrol ve plastik leasing ve faktöring, metal harici mineral ürünleri, metal ürünleri ve makineler, sanayi, teknoloji, tekstil ve deri, telekomünikasyon, toptan satış ve perakende ticaret, turizm, ulaştırma, yiyecek ve içecek) günlük endeks değerleri ile aynı tarihler arasındaki 5 yıllık CDS prim değerleri Investing.com.'dan alınmıştır.

CDS primleri ile sektör endeksleri arasındaki nedensellik analizini kurmadan önce verilere ilişkin tanımlayıcı istatistik değerleri Tablo 1'de gösterilmiştir. Tablo 1'e göre 20 adet sektör endeksleri ile 5 yıllık CDS puan değerlerinin 650'şer adet verisi ele alınmış; bu değerlerin ortalama, basıklık, çarpıklık ve standart sapma değerleri verilmiştir. İncelenen değerler arasında standart sapması en düşük elektrik ve turizm sektörleri, en yüksek toptan satış ve perakende ticaret olmuştur.

Tablo 1. Özet İstatistik Tablosu

\begin{tabular}{llccccccc}
\hline S.Nu. & \multicolumn{1}{c}{ Değişkenler } & $\mathrm{N}$ & Ortalama & Std.Sapma & Basılık & Çarpıklık & En Az & En Fazla \\
\hline 1 & Bankalar & 650 & $1.301,233$ & 176,167 & 3,096 & 0,593 & 935,640 & $1.810,510$ \\
2 & Basit Metaller & 650 & $2.365,001$ & 432,408 & 2,483 & 0,452 & $1.624,310$ & $3.585,990$ \\
3 & Bilgi Teknolojileri & 650 & 312,568 & 161,175 & 2,493 & 0,945 & 151,450 & 698,320 \\
4 & Elektrik & 650 & 43,083 & 13,502 & 3,650 & 1,263 & 27,870 & 81,810 \\
5 & Finansal & 650 & $1.141,645$ & 128,229 & 3,148 & 0,677 & 897,860 & $1.499,360$ \\
6 & Gayrimenkul Yatırımları & 650 & 365,302 & 99,066 & 2,776 & 0,957 & 239,910 & 625,980 \\
7 & Hizmet & 650 & 811,130 & 134,215 & 2,461 & 0,845 & 618,330 & $1.139,330$ \\
8 & Holding ve Yatırımlar & 650 & 880,402 & 96,863 & 2,754 & 0,494 & 659,150 & $1.160,370$ \\
9 & Petrol ve Plastik & 650 & $1.132,092$ & 117,221 & 4,590 & 0,447 & 776,250 & $1.572,460$ \\
10 & Leasing ve Faktöring & 650 & 753,380 & 224,001 & 2,528 & 0,447 & 422,690 & $1.410,370$ \\
11 & Metal Harici Mineral & 650 & 814,992 & 262,326 & 4,674 & 1,571 & 544,810 & $1.727,660$ \\
& Ürünleri & & & & & & & \\
12 & Metal Ürün ve Mak. & 650 & $1.581,711$ & 404,028 & 4,409 & 1,398 & $1.078,590$ & $2.957,700$ \\
13 & Sanayi & 650 & $1.290,772$ & 222,342 & 4,715 & 1,452 & 988,370 & $2.069,460$ \\
14 & Teknoloji & 650 & $1.129,659$ & 318,857 & 2,656 & 0,938 & 709,420 & $1.884,220$ \\
15 & Tekstil ve Deri & 650 & 401,210 & 146,136 & 2,820 & 1,026 & 247,470 & 799,010 \\
16 & Telekomünikasyon & 650 & $1.129,659$ & 318,857 & 2,656 & 0,938 & 709,420 & $1.884,220$ \\
17 & Toptan Satış ve Perakende & 650 & $2.301,556$ & 549,629 & 2,467 & 0,853 & $1.524,130$ & $3.519,700$ \\
& Ticaret & & & & & & \\
18 & Turizm & 650 & 106,318 & 57,232 & 3,815 & 1,394 & 59,820 & 283,250 \\
19 & Ulaştırma & 650 & $1.463,911$ & 178,021 & 3,210 & $-0,079$ & 864,610 & $1.870,530$ \\
20 & Yiyecek ve İçecek & 650 & $1.286,580$ & 262,875 & 3,464 & 1,103 & 945,570 & $2.082,120$ \\
21 & CDS Primleri & 650 & 400,697 & 100,259 & 2,225 & 0,344 & 189,700 & 651,910 \\
\hline
\end{tabular}


Tablo 1'deki özet istatistiki verilere göre özellikle bilgi teknolojileri, elektrik, gayrimenkul yatırımları, leasing ve faktöring,teknoloji, tekstil ve deri, telekomünikasyon ve turizm sektörlerinde diğer sektörlere göre incelenen dönemler arasında daha fazla değişkenliğin olduğu görülmektedir.

Çalışmada için seçilen 21 sektör endeksinin CDS primleri ile olan ilişkisini görmek için Tablo 2'deki korelasyon analizi yapılmıştır. Sektörler ile CDS primleri arasındaki korelasyon analizi sonuçlarına göre CDS primlerindeki yükseliş özellikle Bankacılık, Finans ve Ulaştırma sektörlerinde ters orantı bir ilişkiye sahip olduğu yani söz konusu sektör endekslerinin düştüğü tespit edilmiştir.

Tablo 2. Korelasyon Tablosu

\begin{tabular}{|c|l|c|}
\hline S,Nu, & \multicolumn{1}{|c|}{ Endeks } & $\begin{array}{c}\text { CDS } \\
(5 \text { Ylllık })\end{array}$ \\
\hline 1 & Bankalar & $-0,669^{* * *}$ \\
\hline 2 & Basit Metaller & 0,01 \\
\hline 3 & Bilgi Teknolojileri & $0,438^{* * *}$ \\
\hline 4 & Elektrik & $0,284^{* * *}$ \\
\hline 5 & Finansal & $-0,353^{* * *}$ \\
\hline 6 & Gayrimenkul Yatırımları & $0,232^{* * *}$ \\
\hline 7 & Hizmet & $0,307^{* * *}$ \\
\hline 8 & Holding ve Yatırımlar & $-0,0484$ \\
\hline 9 & Petrol ve Plastik & $0,102^{* *}$ \\
\hline 10 & Leasing ve Faktöring & 0,0733 \\
\hline
\end{tabular}

\begin{tabular}{|c|l|c|}
\hline S,Nu, & \multicolumn{1}{|c|}{ Endeks } & $\begin{array}{c}\text { CDS } \\
(5 \text { Y } 111 \text { lk })\end{array}$ \\
\hline 11 & Metal Harici Mineral Ürünleri & $0,310^{* * *}$ \\
\hline 12 & Metal Ürünleri ve Makineler & $0,220^{* * *}$ \\
\hline 13 & Sanayi & $0,223^{* * *}$ \\
\hline 14 & Teknoloji & $0,453^{* * *}$ \\
\hline 15 & Tekstil ve Deri & $0,338^{* * *}$ \\
\hline 16 & Telekomünikasyon & $0,453^{* * *}$ \\
\hline 17 & Toptan Satış ve Perakende Tic, & $0,462^{* * *}$ \\
\hline 18 & Turizm & $0,381^{* * *}$ \\
\hline 19 & Ulaştırma & $-0,594^{* * *}$ \\
\hline 20 & Yiyecek ve İçecek & $0,252^{* * *}$ \\
\hline
\end{tabular}

Tablo 2‘ye göre ayrıca Türkiye'nin 5 yıllık CDS primi ile telekom, toptan perakende ticaret, bilişim teknolojileri tekstil ve deri, turizm, metal harici mineral ürünleri, hizmet, gayrimenkul yatırım, elektrik, yiyecek, içecek, metal ürünleri ve makine sektörleri arasında orta düzeyde ve pozitif ilişki bulunduğu tespit edilmiştir. Basit metaller, holding yatırım, leasing ve factoring sektörlerinin Türkiye'nin 5 yıllık CDS Puanı ile oldukça zayıf ilişkisinin olduğu gözlemlenmektedir.

CDS primleri ile sektör endeksleri arasındaki nedensellik ilişkisi için diğer bir varsayım olan serilerin birim kök içirip içermediğinin yani durağan olup olmadığının kontrol edilmesi gerekmektedir. İlk olarak yapısal kırılmaları dikkate almayan birinci nesil birim kök testleri ile serilerin durağan olup olmadığına bakılmıştır.

Zaman serisinin durağan olmasından kast edilen ortalaması ve varyansının zaman içinde değişmemesi ve kovaryansının ise dönemler arasındaki gecikmeye bağlı olup zamana bağlı olmaması durumudur (Atik vd., 2015: 254). Zaman serileri durağan olmamas1 durumunda stokastik ya da deterministik trend içerecektir. Durağan bir zaman serisinin ortalamas1, varyansı ve kovaryansı zamandan bağımsı olmakta, zaman içinde değişmemektedir. Böyle bir zaman serisi kendi ortalaması etrafında sabit genişlikte salınımlar gösterecektir. Serinin bu özelliğine ortalamaya dönüş (mean reversion) denilmektedir. Durağan seriler literatürde zayıf durağan (weakly stationary), kovaryans durağan (covariance stationary) şeklinde farklı isimlerle de kullanılmaktadır. Durağanlılığı açıklamak için $Y_{t}$ 'nin bir seri olduğu farz edildiğinde; 


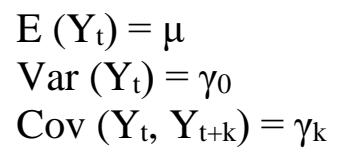

Başlangıç noktasını $t$ noktasından, $t+k$ 'ya getirdiğimizde eğer $Y_{t}$ serisi durağan ise $Y_{t}$, ve $Y_{t+k}$ serilerinin ortalama, varyans ve kovaryanslarının aynı olması gerekmektedir. Ancak $k$, 0 ise $\operatorname{Cov}\left(Y_{t}, Y_{t+0}\right)=\operatorname{Var}\left(Y_{t}\right)=\sigma^{2}$ şeklinde olacaktır.

Zaman serisi durağan değil (durağan dışı- non stationary) ise serinin ortalaması, varyansı veya her ikisi birden zamana bağlı olarak değişecektir. Seri durağan olmaması durumunda serinin davranışı diğer dönemler için genellenemez ve geleceği tahmin etmek için kullanılamaz (Yalta, 2011).

$\mathrm{Bu}$ yüzden serinin durağanlığını kontrol etmek için birinci nesil testlerinden Augmented Dickey Fuller (ADF) birim kök testleri kullanılmıştır. ADF testi, hata terimlerinin farklı varyans ve seri korelasyon içerecek şekilde rassal ve homojen dağıldıkları varsayımını kontrol etmek için kullanılmaktadır. Değişkenlerin durağanlılığ trend içerip, sahte regresyon ortaya çıkacaktır (Gujarati, 2006:713-724).

$$
\Delta Y_{t}=\beta_{1}+\beta_{2 \cdot} t+\delta . Y_{t-1}+\alpha_{i \cdot} \sum_{i=1}^{m} \Delta Y_{t-i}+\varepsilon_{t}
$$

$\Delta \mathrm{Yt}=$ Durağanlı̆̆

$\mathrm{t}=$ Trend değişkenini,

$\Delta \mathrm{Y}_{\mathrm{t}-\mathrm{i}}=$ Gecikmeli fark1,

$\varepsilon_{\mathrm{t}}=$ Ortalaması 0 , ardışık bağımlılı̆ğ olmayan, varyansı değişmeyen hata terimidir.

ADF birim kök testinde,

$$
\begin{aligned}
& \mathrm{H}_{0}=\alpha_{1}=0 \\
& \mathrm{H}_{1}=\alpha_{1}<0
\end{aligned}
$$

şeklinde olup, $\mathrm{H}_{0}$ 'ın red edilmesi serinin durağan olup, birim kök içermediği anlamına gelmektedir. Tablo 3 'te ADF birim kök test sonuçları verilmiştir. 
Tablo 3. Augmented Dickey-Fuller Birim Kök Test Sonuçları

\begin{tabular}{|c|c|c|c|c|c|c|c|c|}
\hline \multirow{3}{*}{ Endeks } & \multicolumn{4}{|c|}{$\mathrm{I}_{0}$} & \multicolumn{4}{|c|}{$\mathrm{I}_{1}$} \\
\hline & \multicolumn{2}{|c|}{ Sabit } & \multicolumn{2}{|c|}{ Trend + Sabit } & \multicolumn{2}{|c|}{ Sabit } & \multicolumn{2}{|c|}{ Trend + Sabit } \\
\hline & T-İstatistik & Olasılık & T-İstatistik & Olasılık & T-İstatistik & Olasılık & T-İstatistik & Olasılık \\
\hline Bilgi Teknolojileri & 0,886 & 0,995 & $-1,980$ & 0,611 & $-21,679$ & 0,000 & $-21,843$ & 0,000 \\
\hline Bankalar & $-2,285$ & 0,177 & $-2,407$ & 0,375 & $-24,633$ & 0,000 & $-24,630$ & 0,000 \\
\hline Basit Metaller & $-0,347$ & 0,915 & $-0,477$ & 0,984 & $-27,421$ & 0,000 & $-27,616$ & 0,000 \\
\hline CDS Prim & $-2,823$ & 0,056 & $-2,738$ & 0,221 & $-29,503$ & 0,000 & $-29,512$ & 0,000 \\
\hline Elektrik & 1,507 & 0,999 & $-0,984$ & 0,944 & $-24,048$ & 0,000 & $-24,349$ & 0,000 \\
\hline Finansallar & $-1,542$ & 0,512 & $-2,547$ & 0,305 & $-24,656$ & 0,000 & $-24,681$ & 0,000 \\
\hline $\begin{array}{l}\text { Gayrimenkul } \\
\text { Yatırımları }\end{array}$ & 0,854 & 0,995 & $-1,438$ & 0,849 & $-38,431$ & 0,000 & $-38,666$ & 0,000 \\
\hline Hizmet & 0,184 & 0,972 & $-2,697$ & 0,238 & $-15,492$ & 0,000 & $-15,553$ & 0,000 \\
\hline $\begin{array}{l}\text { Holding ve } \\
\text { Yatırımlar }\end{array}$ & $-0,803$ & 0,817 & $-1,994$ & 0,603 & $-24,784$ & 0,000 & $-24,803$ & 0,000 \\
\hline $\begin{array}{l}\text { Leasing ve } \\
\text { Faktöring }\end{array}$ & $-1,702$ & 0,430 & $-1,882$ & 0,663 & $-22,516$ & 0,000 & $-22,506$ & 0,000 \\
\hline $\begin{array}{l}\text { Metal Harici } \\
\text { Mineral Ürünleri }\end{array}$ & 2,680 & 1,000 & 0,344 & 0,999 & $-24,778$ & 0,000 & $-25,242$ & 0,000 \\
\hline $\begin{array}{l}\text { Metal Ürünleri ve } \\
\text { Makineler }\end{array}$ & 1,795 & 1,000 & $-0,479$ & 0,984 & $-22,496$ & 0,000 & $-22,749$ & 0,000 \\
\hline Petrol ve Plastik & $-0,406$ & 0,906 & $-1,231$ & 0,903 & $-23,684$ & 0,000 & $-23,715$ & 0,000 \\
\hline Sanayi & 1,831 & 1,000 & $-0,526$ & 0,982 & $-15,228$ & 0,000 & $-15,446$ & 0,000 \\
\hline Teknoloji & 0,065 & 0,963 & $-1,491$ & 0,832 & $-26,291$ & 0,000 & $-26,381$ & 0,000 \\
\hline Tekstil ve Deri & 0,711 & 0,992 & $-1,940$ & 0,632 & $-11,210$ & 0,000 & $-11,382$ & 0,000 \\
\hline Telekomünikasyon & 0,065 & 0,963 & $-1,491$ & 0,832 & $-26,291$ & 0,000 & $-26,381$ & 0,000 \\
\hline $\begin{array}{l}\text { Toptan Satış ve } \\
\text { Perakende Ticaret }\end{array}$ & 0,160 & 0,970 & $-2,151$ & 0,516 & $-24,057$ & 0,000 & $-24,089$ & 0,000 \\
\hline Turizm & 2,522 & 1,000 & $-0,004$ & 0,996 & $-23,251$ & 0,000 & $-23,546$ & 0,000 \\
\hline Ulaştırma & $-2,741$ & 0,068 & $-2,743$ & 0,220 & $-25,150$ & 0,000 & $-25,144$ & 0,000 \\
\hline Yiyecek ve İçecek & 0,554 & 0,988 & $-2,240$ & 0,466 & $-22,998$ & 0,000 & $-23,135$ & 0,000 \\
\hline
\end{tabular}

Tablo 3'e göre serilerin tamamının düzeyde $\left(\mathrm{I}_{0}\right)$ durağan olmadığ farkları alındıktan sonra ise durağan oldukları tespit edilmiş ve seçilen endeks değerleriyle CDS prim değeri arasında nedensellik ilişkisi Granger Nedensellik Analizi ile test edilmiştir. Granger nedensellik analiz sonuçları Tablo 4 'te sunulmuştur.

Tablo 4. Granger Nedensellik Analiz Sonuçları

\begin{tabular}{|c|l|c|c|c|l|}
\hline Model & \multicolumn{1}{|c|}{ İlişkinin Yönü } & $\mathrm{X}^{2}$ & $\mathrm{Sd}$ & $\mathrm{p}$ Değeri & \multicolumn{1}{|c|}{ Açıklama } \\
\hline \multirow{2}{*}{1} & CDS $\rightarrow$ Bilgi Teknolojileri & 11,782 & 3 & 0,008 & Nedensellik İlişkisi Vardır. \\
\cline { 2 - 6 } & Bilgi Teknolojileri $\rightarrow$ CDS & 55,343 & 3 & 0,000 & Nedensellik İlişkisi Vardır. \\
\hline \multirow{2}{*}{2} & CDS $\rightarrow$ Banka & 9,737 & 2 & 0,008 & Nedensellik İlişkisi Vardır. \\
\cline { 2 - 6 } & Bankalar $\rightarrow$ CDS & 144,884 & 2 & 0,000 & Nedensellik İlişkisi Vardır. \\
\hline \multirow{2}{*}{3} & CDS $\rightarrow$ Basit Metaller & 12,932 & 2 & 0,002 & Nedensellik İlişkisi Vardır. \\
\cline { 2 - 6 } & Basit Metaller $\rightarrow$ CDS & 35,233 & 2 & 0,000 & Nedensellik İlişkisi Vardır. \\
\hline \multirow{2}{*}{4} & CDS $\rightarrow$ Elektrik & 8,460 & 2 & 0,015 & Nedensellik İlişkisi Vardır. \\
\cline { 2 - 6 } & Elektrik $\rightarrow$ CDS & 42,514 & 2 & 0,000 & Nedensellik İlişkisi Vardır. \\
\hline \multirow{2}{*}{5} & CDS $\rightarrow$ Finansal & 11,248 & 2 & 0,004 & Nedensellik İlişkisi Vardır. \\
\cline { 2 - 6 } & Finansal $\rightarrow$ CDS & 149,175 & 2 & 0,000 & Nedensellik İlişkisi Vardır. \\
\hline \multirow{2}{*}{6} & CDS $\rightarrow$ Gayrimenkul Yatırımları & $\mathbf{0 , 0 5 9}$ & $\mathbf{1}$ & $\mathbf{0 , 8 0 8}$ & Nedensellik İlişkisi Yoktur. \\
\cline { 2 - 6 } & Gayrimenkul Yatırımları $\rightarrow$ CDS & $\mathbf{1 , 2 7 3}$ & $\mathbf{1}$ & $\mathbf{0 , 2 5 9}$ & Nedensellik İlişkisi Yoktur. \\
\hline
\end{tabular}




\begin{tabular}{|c|c|c|c|c|c|}
\hline \multirow{2}{*}{7} & $\mathrm{CDS} \rightarrow$ Hizmet & 12,618 & 5 & 0,027 & Nedensellik İlişkisi Vardır. \\
\hline & Hizmet $\rightarrow$ CDS & 108,995 & 5 & 0,000 & Nedensellik İlişkisi Vardır. \\
\hline \multirow{2}{*}{8} & CDS $\rightarrow$ Holding ve Yatırımlar & 14,032 & 2 & 0,001 & Nedensellik İlişkisi Vardır. \\
\hline & Holding ve Yatırımlar $\rightarrow$ CDS & 97,257 & 2 & 0,000 & Nedensellik İlişkisi Vardır. \\
\hline \multirow{2}{*}{9} & CDS $\rightarrow$ Leasing ve Faktöring & 1,098 & 2 & 0,578 & Nedensellik İlişkisi Yoktur. \\
\hline & Leasing ve Faktöring $\rightarrow$ CDS & 25,083 & 2 & 0,000 & Nedensellik İlişkisi Vardır. \\
\hline \multirow{2}{*}{10} & CDS $\rightarrow$ Metal Harici Mineral Ürünleri & 3,658 & 2 & 0,161 & Nedensellik İlișkisi Yoktur. \\
\hline & Metal Harici Mineral Ürünleri $\rightarrow$ CDS & 45,697 & 2 & 0,000 & Nedensellik İlişkisi Vardır. \\
\hline \multirow{2}{*}{11} & CDS $\rightarrow$ Metal Ürünleri ve Makineler & 7,432 & 2 & 0,024 & Nedensellik İlişkisi Vardır. \\
\hline & Metal Ürünleri ve Makineler $\rightarrow$ CDS & 51,901 & 2 & 0,000 & Nedensellik İlişkisi Vardır. \\
\hline \multirow{2}{*}{12} & $\mathrm{CDS} \rightarrow$ Petrol ve Plastik & 0,027 & 1 & 0,869 & Nedensellik İlişkisi Yoktur. \\
\hline & Petrol ve Plastik $\rightarrow$ CDS & 31,512 & 1 & 0,000 & Nedensellik İlişkisi Vardır. \\
\hline \multirow{2}{*}{13} & $\mathrm{CDS} \rightarrow$ Sanayi & 11,648 & 2 & 0,003 & Nedensellik İlişkisi Vardır. \\
\hline & Sanayi $\rightarrow$ CDS & 74,314 & 2 & 0,000 & Nedensellik İlişkisi Vardır. \\
\hline \multirow{2}{*}{14} & CDS $\rightarrow$ Teknoloji & 5,914 & 4 & 0,206 & Nedensellik İlişkisi Yoktur. \\
\hline & Teknoloji $\rightarrow$ CDS & 87,725 & 4 & 0,000 & Nedensellik İlişkisi Vardır. \\
\hline \multirow{2}{*}{15} & CDS $\rightarrow$ Tekstil ve Deri & 10,808 & 5 & 0,055 & Nedensellik İlişkisi Yoktur. \\
\hline & Tekstil ve Deri $\rightarrow$ CDS & 91,174 & 5 & 0,000 & Nedensellik İlişskisi Vardır. \\
\hline \multirow{2}{*}{16} & CDS $\rightarrow$ Telekomünikasyon & 5,914 & 4 & 0,206 & Nedensellik İlişkisi Yoktur. \\
\hline & Telekomünikasyon $\rightarrow$ CDS & 87,725 & 4 & 0,000 & Nedensellik İlişkisi Vardır. \\
\hline \multirow{2}{*}{17} & CDS $\rightarrow$ Top.Sat.Per.Tic. & 1,173 & 1 & 0,279 & Nedensellik İlişkisi Yoktur. \\
\hline & Top.Sat.Per.Tic. $\rightarrow$ CDS & 27,255 & 1 & 0,000 & Nedensellik İlişkisi Vardır. \\
\hline \multirow{2}{*}{18} & CDS $\rightarrow$ Turizm & 10,375 & 2 & 0,006 & Nedensellik İlişkisi Vardır. \\
\hline & Turizm $\rightarrow$ CDS & 52,595 & 2 & 0,000 & Nedensellik İlişkisi Vardır. \\
\hline \multirow{2}{*}{19} & $\mathrm{CDS} \rightarrow$ Ulaştırma & 18,321 & 2 & 0,000 & Nedensellik İlişkisi Vardır. \\
\hline & Ulaştırma $\rightarrow$ CDS & 60,785 & 2 & 0,000 & Nedensellik İlişskisi Vardır. \\
\hline \multirow{2}{*}{20} & CDS $\rightarrow$ Yiyecek ve İçecek & 5,323 & 2 & $\mathbf{0 , 0 7 0}$ & Nedensellik İlişkisi Yoktur. \\
\hline & Yiyecek ve İçecek $\rightarrow$ CDS & 51,943 & 2 & 0,000 & Nedensellik İlişkisi Vardır. \\
\hline
\end{tabular}

Not: Her bir model için kurulan VAR modelinde serbestlik derecesinde durağan ve otokorelasyon problemi bulunmamaktadır. Her bir değişkenin başında bulunan d harfi, seriyi durağan hale getirmek için birinci dereceden farklının alındığını göstermektedir.

\section{BULGULAR}

Yapılan granger nedensellik analizi sonucunda CDS prim değerleri ile bilgi teknolojileri, bankalar, basit metaller, elektrik, finansal, hizmet, holding yatırım, metal ürünleri ve makine, sanayi, turizm, ulaştırma sektörleri arasında çift yönlü granger nedenselliği; gayrimenkul sektör endeksi ile granger nedensellik ilişkisinin bulunmadığı, leasing factoring ve metal harici mineral ürünleri, kimyasal, petrol ve plastik sektör, teknoloji, tekstil ve deri, telekom, toptan ve perakende satış ve yiyecek içecek sektör endekslerinden CDS primlerine tek yönlü nedensellik ilişkisinin bulunduğu tespit edilmiştir. İncelenen sektörlerde sadece gayrimenkul sektör endeksi ile CDS Prim değeri arasında incelenen dönemler için hiçbir nedensellik ilişkisinin bulunmadığı belirlenmiştir. Ülkelerin finansal risklilik seviyelerinin sektör endeksi üzerinde etkisinin olup olmadığı önemlidir. Görüleceği üzere birçok alt sektörde CDS primleri ile sektörler arasında ilişkinin olduğu gözlemlenmiştir. Dolayısıyla ülke risklilik seviyesindeki bir artış veya azalış alt sektörleri etkilemektedir.

\section{SONUÇ VE DEĞERLENDİRME}

CDS, ülkenin borçlarını ödeyememesi riskine karşı yani iflas riskine karşı alacaklının alacaklarını sigortalayan bir sözleşmedir. CDS sözleşmesinin fiyatı o ülkenin CDS primini temsil etmektedir. Bir ülkenin ya da bir şirketin CDS primi ne kadar yüksekse borçlanma maliyeti de o kadar yüksek olmaktadır. CDS yani elinde tahvil vb. finansal araçlar bulunduran bir kişinin, vade sonundaki alacağının belirli bir bedel karşılığında ödenmeme riskinin ortadan 
kaldırılmasına yarayan bir finansal enstrümandır. Ülke CDS'lerinde sigorta konusu, ülkenin dış piyasalarda sattığı tahvillerin ve bonoların anaparalarını veya faizlerini ödeyememe riskidir. Ülkenin CDS primi ne kadar yüksekse, o ülkenin ve ülkede bulunan işletmelerin uluslararası piyasadan borçlanma maliyeti o kadar yüksek olmaktadır. Makroekonomik anlamda CDS primlerinin yüksek olması; ülkede üretilen mal ve hizmetlerin maliyetlerini artıracağı ve dolayısıyla ödemeler dengesini bozacağı bunun da ülkedeki enflasyon, işsizlik ve döviz kuru riskini artırabileceği belirtilebilir.

Günümüzde Türkiye'nin 5 yıllık ortalama CDS puanı USD olarak 313,27 iken, yani borçlanma maliyeti \%3,13 civarlarında iken; USD olarak Amerika'nın 5,620 (\% 0,0562), Fransa'nın 17,550 (\%0,175), Almanya'nın 11,02 (\% 0,11), İtalya'nın $100 \quad(\% 1)$, Yunanistan'ın 97,04 (\%0,97), Japonya'nın 14,85 (\%0,15), Brezilya'nın 174,32 (\%1,74), Arjantin'in ise $1264,45(\% 12,64)$ ' dür. Bu prim değerlerinden anlaşılacağ1 üzere gelişmiş ekonomilere sahip ülkelerin CDS prim değerleri oldukça düşük, gelişmekte olan ülkelerin CDS prim değerleri nispeten yüksektir.

Yapılan bu çalışmada Türkiye'nin ülke olarak borçlanma maliyetini temsil eden CDS prim değerleri ile ülkenin ekonomisinin temel göstergeleri olan birincil sektör endeks değerlerindeki ilişki incelenmiş ve CDS prim değerleri ile incelenen yaklaşık tüm sektör endeks değerleri arasında çift yönlü veya kimilerinde tek yönlü nedensellik ilişkisinin olduğu tespit edilmiştir. Çift yönlü nedensellik ilişkisinde, CDS primindeki değişimlerin herhangi bir alt endeksini etkileyebileceği gibi, alt sektördeki değişimlerin ülke ekonomisi ve dolayısıyla CDS prim değerini etkileyebileceği değerlendirilmektedir. Tek yönlü nedensellik ilişkisi varlığında, alt sektördeki değişimlerin ülke ekonomisi ve dolayısıyla CDS prim değerini etkileyebileceği değerlendirilmektedir. Çalışmada elde edilen bulguların literatürde yer alan çalışmalarla önemli ölçüde benzerlik gösterdiği belirlenmiştir. Bu durum bir ülkenin CDS primlerinin yüksek olduğunda ülkenin riskinin artacağı, uluslararası piyasalarda fonlama maliyetlerini artıracağı, bunun da o ülkede mal ve hizmet üreten tüm sektördeki şirketlerin faaliyetleri için kaynak maliyetlerini olumsuz yönde etkileyebileceği değerlendirilmektedir.

\section{KAYNAKLAR}

Akkaya, Murat (2017), “Türk Tahvillerinin CDS Primlerini Etkileyen İçsel Faktörlerin Analizi”, Maliye Finans Yazıları, Sayı 107, ss.129-146.

Atik, Murat- Köse Yaşar- Yılmaz Bülent- Sağlam Fatih (2015), “Kripto Para: Bitcoin ve Döviz Kurları Üzerine Etkileri”, Bartın Üniversitesi İktisadi ve İdari Bilimler Fakültesi Dergisi, 6 (11), ss. 247-262.

Byström, Hans (2005), “Credit Default Swaps And Equity Prices: The Itraxx Cds Index Market Working Papers”, 24, Lund University, Department of Economics.

Evci, Samet (2020), “Kredi Temerrüt Swapları İle Borsa İstanbul Arasındaki Eşbütütünleşme İlişkisinin Analizi”, Journal of Gaziantep University Faculty of Economics and Administrative Sciences, Vol 2, No.1.

Gujarati, N Damador (2006), “Temel Ekonometri”, (Çev. Ümit Şenesen ve Gülay Günlük Şenesen), Literatür Yayıncılık, İstanbul. 
İskenderoğlu, Ömer - Balat, Asuman (2018), “Ülke Kredi Notlarının CDS Primleri Üzerindeki Etkisi: BRICS Ülkeleri ve Türkiye Üzerine Bir Uygulama”, BDDK Bankacılık ve Finansal Piyasalar, Cilt 12, Sayı 2, ss.47-64.

Kılcı, N. Esra (2017), “CDS primleri ile ülke kredi riski arasındaki ilişkinin değerlendirilmesi; Türkiye örneği”, Maliye Finans Yazıları, 108, ss.71-86.

Križanič, France. - Oplotnik Zan Jan (2015), “The CDS and the Government Bonds Markets During the Last Financial Crisis”, Zagreb International Review of Economics \& Business, Vol. 18, No. 2.

Lau, Jorge Chan. - Kim, Yoon Sook (2004) "Equity Prices, Credit Default Swaps, and Bond Spreads in Emerging Markets”, IMF Working Paper.

Norden, Lars - Weber, Martin (2004), “Informational efficiency of credit default swap and stock markets: The impact of credit rating announcements", Journal of Banking \& Finance, pp.2813-2843.

Sarı̈ül, Haşmet. - Şengelen, Hakan Eren. (2020), “Ülke kredi temerrüt takas primleri ile hisse senedi fiyatları arasındaki ilişki: Borsa İstanbul'da banka hisse senetleri üzerine ampirik bir araştırma” Muhasebe ve Finansman Dergisi, 86, ss.247-264.

Yağcılar, Gamze Göçmen - Arslan, Zühal (2020), "Gelişmekte Olan Ülkelerin CDS Primleri Arasındaki Eş-bütünleşme ve Nedensellik İlişkilerinin Araştırılması”, İşletme Araştırmaları Dergisi, 12(3), pp.2461-2475.

https://www.investopedia.com/articles/optioninvestor/08/cds.asp1, (12.12.2020).

https://www.isda.org/a/JUPTE/Global-CDS-Market-Study.pdf., (12.12.2020).

https://tr.investing.com/rates-bonds/turkey-cds-6-months-usd, (12.12.2020).

https://tr.investing.com/rates-bonds/turkey-cds-5-years-usd, (12.12.2020). 